\title{
Seroprevalence of campylobacteriosis and relevant post-infectious sequelae
}

\author{
A. E. Zautner • C. Johann • A. Strubel • C. Busse • \\ A. M. Tareen $\cdot$ W. O. Masanta $\cdot$ R. Lugert • \\ R. Schmidt-Ott • U. Groß
}

Received: 12 September 2013 / Accepted: 16 December 2013 / Published online: 12 January 2014

(C) The Author(s) 2014. This article is published with open access at Springerlink.com

\begin{abstract}
Post-infectious sequelea such as Guillain Barré syndrome (GBS), reactive arthritis (RA), and inflammatory bowel disease (IBD) may arise as a consequence of acute Campylobacter-enteritis (AE). However, reliable seroprevalence data of Campylobacter-associated sequelae has not been established. The objectives of this study were, first, to identify the most specific and sensitive test antigen in an optimized ELISA assay for diagnosing a previous Campylobacter-infection and, second, to compare the prevalence of antiCampylobacter antibodies in cohorts of healthy blood donors (BD), AE, GBS, RA, and IBD patients with antibodies against known GBS, RA and IBD triggering pathogens. Optimized ELISAs of single and combined Campylobacter-proteins OMP18 and P39 as antigens were prepared and sera from AE, GBS, RA and IBD patients and BD were tested for Campylobcter-specific IgA and IgG antibodies. The results were compared with MIKROGEN ${ }^{\mathrm{TM}}$-recomLine Campylobacter $\operatorname{IgA} / \operatorname{IgG}$ and whole cell lysate-immunoblot. Antibodies specific for Helicobacter pylori, Mycoplasma pneumoniae, Yersinia enterocolitica, and Borrelia afzelii were tested with commercial immunoblots. ROC plot analysis revealed AUC maxima in the combination of OMP18 and P39
\end{abstract}

\footnotetext{
A. E. Zautner - C. Johann - A. M. Tareen - W. O. Masanta •

R. Lugert $\cdot$ R. Schmidt-Ott $\cdot$ U. Groß

Institut für Medizinische Mikrobiologie, Universitätsmedizin

Göttingen, Kreuzbergring 57, 37075 Göttingen, Germany
}

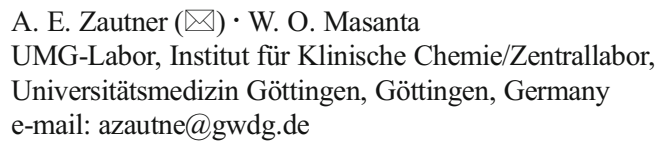

A. Strubel $\cdot$ C. Busse

Sekisui Virotech GmbH, Rüsselsheim, Germany

Present Address:

R. Schmidt-Ott

GlaxoSmithKlineVaccines, Wavre, Belgium for IgA and in the P39-antigen for IgG. As a result, 34-49\% GBS cases, 44-62\% RA cases and 23-40\% IBD cases were associated with Campylobacter-infection. These data show that Campylobcater-seropositivity in these patient groups is significantly higher than other triggering pathogens suggesting that it plays an important role in development of GBS and $\mathrm{RA}$, and supports the hypothesis that recurrent acute campylobacteriosis triggers IBD.

\section{Introduction}

Members of genus Campylobacter are Gram-negative and microaerophilic bacteria that invade the gastrointestinal tract of humans causing campylobacteriosis whose clinical symptoms include bloody or watery diarrhea, abdominal pain, fever, headache, nausea and vomiting. Although this acute enteritis is self-limiting, post-infectious sequelae GBS, RA and IBD can arise after recovery [1-3]. Recently, C. jejuni has been found to be the leading cause of bacterial gastroenteritis worldwide [4, 5], which has led to renewed interest in quantifying the seroprevalence of Campylobacter-specific antibodies in the rising cases of GBS, RA and IBD as postinfectious sequelae.

Recent studies have shown GBS an autoimmune disorder in which the body's immune system attacks GM-gangliosides in the central nervous system leading to acute neuromuscular paralysis and consecutive muscle weakness succeeding campylobacteriosis [6]. Furthermore, cytomegaloviruses (CMV), Epstein-Barr viruses (EBV) and Mycoplasma pneumonia have been shown to trigger GBS [6]. Presently, four common types of GBS are recognized vis-á-vis the Miller Fisher syndrome (MFS), the acute motor axonal neuropathy (AMAN), the acute inflammatory demyelinating polyradiculoneuropathy (AIDP) and the acute motor-sensory axonal neuropathy (AMSAN) [6]. Importantly, 
Campylobacter has been linked to trigger MFS, AMAN, and AMSAN [6].

Similarly, RA has been shown to develop after campylobacteriosis [7-9]. Like in GBS, other pathogens including Salmonella enterica, Shigella dysenteriae, Yersinia enterocolitica, Yersinia pseudotuberculosis, and Chlamydia trachomatis have been implicated in triggering RA [7]. In previous studies the incidence of $\mathrm{RA}$ in acute campylobacteriosis patients was found to range from 1 to $7 \%$ [7, 10]. However, seroprevalence data in RA patients, with an acute flare up of arthritis has not been estimated so far.

Equivalently, epidemiologic, ecologic and genetic studies have associated the pathogenesis of IBD, a strictly gastrointestinal tract immunological disorder, with interplay between C. jejuni, host genetic susceptibility, recurrent AE, and commensal microflora [11-15]. It has been revealed that host genetics influences the diversity and load of commensal microflora. However, slight alteration in diversity and loads of members of the commensal microflora of phyla Firmicutes and Bacterioidetes due to diet and other unknown agents, promotes intestinal epithelial invasion by $C$. jejuni leading to development of IBD [15-17].

The Campylobacter literature shows inconsistence in the frequency of previous Campylobacter infections in these sequelae. As a consequence, there is under- or over-estimation of Campylobacter-triggered post infectious sequelae. This has been attributed to lack of reliable serological assays for detecting previous Campylobacter infections due to poor standardization and cross-reactivity to other pathogens including Helicobacter spp., Arcobacter spp., Salmonella spp., Legionella spp., Yersinia spp., and Corynebacterium spp. [18-20].

Recently, we reported on a Campylobacter ELISA with $91.9 \%$ sensitivity and $99.0 \%$ specificity that is reliable for detecting previous Campylobacter antibodies in healthy individuals (BD), AE-patients and GBS-patients [21]. This assay is based on a combination of two purified Campylobacter antigens, namely, OMP18 and P39 [22]. However, the most specific and sensitive antigen or antigen combination for the detection of previous Campylobacter infection in a particular post-infectious sequel remains unknown. Furthermore, the ability of antigens OMP18 and P39 to diagnose previous Campylobacter infection in RA-patients and IBD-patients is also unknown. Clearly, knowledge of the specificity and sensitivity of antigens OMP18 and P39 is important for continuous development of reliable assays for detecting previous Campylobacter infections in a particular post-infectious sequel.

In the present study, we investigated the most specific and sensitive antigen between OMP18, P39 and combined OMP18+P39 for detecting Campylobacter specific antibodies in AE-patients and patients of each named post-infectious sequel; we tested sensitivity and specificity of optimized
OMP18 and P39 ELISA in detecting prior Campylobacter infections by comparing it's results with those of antigens MOMP, PEB1, PEB2, PEB4, OMP18, and P39 embedded in MIKROGEN ${ }^{\mathrm{TM}}$-recomLine Campylobacter $\operatorname{IgA} / \operatorname{IgG}$ blot and of a whole cell lysate immunoblot [23]; we used the optimized OMP18+P39 and P39 ELISA to determine the seroprevalance of Campylobacter specific IgA and IgG antibodies in BD, AE, GBS, RA, and IBD respectively; we tested BD, AE, GBS, RA, and IBD sera for the presence of antibodies against Helicobacter pylori and Yersinia enterocolitica which are known to cross-react with Campylobacter antigens [24] and Mycoplasma pneumonia and Borrelia afzelii that cause similar clinical symptoms as those observed in campylobacteriosis associated post-infectious sequelae.

\section{Materials and methods}

Sera tested in the study

Sera tested in this study were collected from 91 GBS patients, 60 AE patients, 50 RA patients, 39 IBD patients and 80 BD.

The GBS cohort comprised of three sera from confirmed MFS patients and the remaining 88 were AMAN, AIDP and AMSAN suspected cases, which had not been clinically distinguished. Mean age of the patients was $61.2 \pm 17.1$ years; the age median was $66.0 \pm 13.6$ years and the proportion of male to female patients was $46.8 \%: 53.2 \%$. The sera of patients with acute diarrhea and a Campylobacter-positive stool culture were included as positive control. The mean age of AE patients was $47.5 \pm 24.3$ years, the age median was $51.0 \pm$ 21.1 years, and the proportion of male to female patients was $59.3 \%: 40.7 \%$. The mean age of RA patients was $39.7 \pm 22.0$ years, the age median was $43.5 \pm 19.5$ years and the proportion of male to female patients was $48.0 \%: 52.0 \%$. The serum samples were collected at an acute flare-up stage of arthritis. The IBD patient group's age mean was $37.3 \pm$ 21.5 years, the age median was $38 \pm 18.2$ years, and the proportion of male to female patients was $40.7 \%: 59.3 \%$. The mean age of BDs was $39.2 \pm 21.3$ years, the age median was $42.2 \pm 20.1$ years, and the proportion of male to female patients was $48.4 \%: 52.6 \%$. BD sera were taken in July 2011 to serve as control group to estimate the seroprevalence of Campylobacter-specific antibodies in healthy individuals. All patients had been hospitalized in the University Medical Center Göttingen from 2001 to 2011 but there were no GBS cases in 2004 and 2005 . All sera were stored at $-80{ }^{\circ} \mathrm{C}$ until testing.

\section{Optimized ELISA assays}

ELISA embedded with $C$. jejuni proteins P39 and OMP18 as antigens, singularly and combined, were prepared. Initially, 
the recombinant proteins $\mathrm{P} 39$ and OMP18 were expressed and purified as described before [22]. Then both proteins were diluted in bicarbonate buffer $(\mathrm{pH}=8.4)$ to a final concentration of $3.0 \mu \mathrm{g} / \mathrm{mL}$ of P39 and $5.0 \mu \mathrm{g} / \mathrm{mL}$ of OMP 18 . NuncMaxiSorp ${ }^{\circledR}$ 96-well plates (Thermo Fisher Scientific Inc., Langenselbold, Germany) were coated with $100 \mu \mathrm{L}$ protein solution of $\mathrm{P} 39$ or OMP18 or $\mathrm{P} 39+\mathrm{OMP} 18$ at room temperature overnight in a wet chamber. After the coating procedure, the plates were washed three times with phosphate-buffered saline (PBS). Thereafter the plates were blocked with $1.0 \%$ BSA in PBS for one hour at room temperature followed by lyophilization. After lyophilization the plates were stored dry. The measurement procedure was performed as described before [22], but with some modifications. First, the patient sera were used at 1:100 dilutions. The secondary horseradish peroxidase-labeled goat anti-human IgA and IgG antibodies were used at a dilution of 1:4000 (anti-human IgA) and 1:50,000 (anti-human IgG; KPL, Gaithersburg, USA). Therewith, we significantly increased the amount of antigen used and decreased the concentration of the secondary antibody in order to achieve higher sensitivity than previously described [22]. Signal intensities above the cut-off value $10.0+1.0$ Virotec units (VU=10*ODsample/OD-Cut-Off) were considered as positive, below the cutoff value $10.0-1.0 \mathrm{VU}$ were considered as negative, and in the range of cut-off value $10.0+/-1.0 \mathrm{VU}$ were considered as borderline.

MIKROGEN-recomLine Campylobacter blot and whole cell lysate-immunoblot

$\mathrm{AE}$ and GBS patient and BD sera were tested on MIKROGENrecomLine Campylobacter IgA/IgG blot and whole cell lysateimmunoblot. Analysis using the well-established recomLineCampylobacter IgA and IgG blot (MIKROGEN Diagnostik, Neuried, Germany) was done as recommended by the manufacturer. On the other hand, the whole cell-lysate (WCL) line-blot was prepared and measurement carried out as previously described [23]. The evaluation of the sera on the whole cell lysate-immunoblot was determined by their responses to PEB1, PEB2, PEB3 and PEB4 antigens [23].

\section{Helicobacter, Mycoplasma, Yersinia, and Borrelia immunoblots}

Helicobacter pylori LINE, Mycoplasma pneumonia LINE, Yersinia enterocolitica LINE, and Borrelia LINE Immunoblot assays (Sekisui Virotech $\mathrm{GmbH}$, Rüsselsheim, Germany) were used for the detection of antibodies against Helicobacter pylori, Mycoplasma pneumoniae, Yersinia enterocolitica, and Borrelia afzelii, respectively. The prevalence of $\operatorname{IgG}$ and $\operatorname{IgA}$ antibodies against these pathogens was determined in all sera except against $B$. afzelii where only the prevalence of $\operatorname{IgG}$ was determined.
Statistical analyses

The $\chi^{2}$-test was used to test for significant differences. The obtained $p$-values are indicated as '*' $(p>0.05),{ }^{\text {'**' }}(p<0.05)$, or ' $* * *$ ' $(p<0.001)$ as shown in Table 2. Calculation of ROC curves and their comparison was performed using the ROCExcel-Tool (ACOMED Statistik, Leipzig, Germany).

\section{Results}

Determination of OMP18, P39 and OMP18+P39 ROC AUC values during detection of Campylobacter specific antibodies in $\mathrm{BD}, \mathrm{AE}, \mathrm{GBS}, \mathrm{RA}$ and IBD

Evaluation of OMP18, P39, and OMP18+P39 AUCs revealed that ELISA embedded with antigen combination OMP18+P39 has a significant advantage in Campylobacterspecific IgA detection as compared to ELISA embedded with OMP18 in AE sera ( $p<0.05$; Fig. 1a), in GBS sera $(p<0.05$; Fig. 1b) and to ELISA embedded with antigen P39 tested with GBS sera $(p<0.05$; Fig. 1c). The comparison of AUCs for the detection of Campylobacter-specific IgG antibodies showed no significant differences between ELISAs embedded with OMP18, P39, and OMP18+P39 except AUC of ELISA embedded with $\mathrm{P} 39$ which was significantly larger as compared to AUC of ELISA embedded with OMP18+P39 $(p<0.05$; Fig. 1d) testing GBS sera. ROC AUCs of antigens MOMP, PEB1, PEB2, and PEB4 and WCL were significantly smaller compared to antigens OMP18, P39 and OMP18+P39 for both IgA and IgG (results not shown).

Table 1 lists sensitivity, specificity, positive predictive values (PPV) and negative predictive values (NPV) of tested individual antigens OMP18, P39, MOMP, PEB1, PEB2, and PEB4 as well as the combined antigens OMP18+P39, and whole cell lysate estimated on sera of stool culture positive campylobacteriosis patients and healthy blood donors. With a specificity of approximately $90 \%$ the OMP 18, P39 and OMP18+P39-based ELISAs showed a sensitivity of $57.1 \%$, $40.7 \%$, and $38.9 \%$, respectively, when tested for IgA and $51.9 \%, 57.4 \%$, and $47.3 \%$, respectively, when tested for IgG. OMP18 and P39 tested on MIKROGEN recomLine blot demonstrated $\approx 10 \%$ increase in specificity and $\approx 15 \%$ decrease in sensitivity. In contrast, antigens MOMP, PEB1, PEB2, and PEB4 tested on MIKROGEN recomLine blot showed $0.0-18.3 \%$ sensitivity when specificity of nearly $100 \%$ was achieved. The selection of the cut-off is based on optical density raw data in a non-prametric approach. As shown by the calculated MIKROGEN evaluation index (Table 1), MOMP, PEB1, PEB2, and PEB4 resulted in $8 \%$ increase in the specificity of $\operatorname{IgA}$ detection as compared to OMP18+P39 ELISA. The sensitivity and specificity of IgG antibody detection was reduced by $7 \%$ as compared to that of 
Fig. 1 Receiver operating characteristic (ROC) curves comparing the antigens/antigencombinations $\mathrm{P} 18$, P39, and $\mathrm{P} 39+\mathrm{P} 18$ for the detection of anti-Campylobacter antibodies. a Sera of culture-positive acute Campylobacter-enteritis patients tested for anti-Campylobacter IgA. b, c Sera of GBS patients tested for anti-Campylobacter IgA. d GBS patients tested for anti-Campylobacter IgG. AUC area under the curve, $S E$ standard error, 0.95 low./upp. $C L 0.95$ lower and upper confidence limits, $p$ p-value
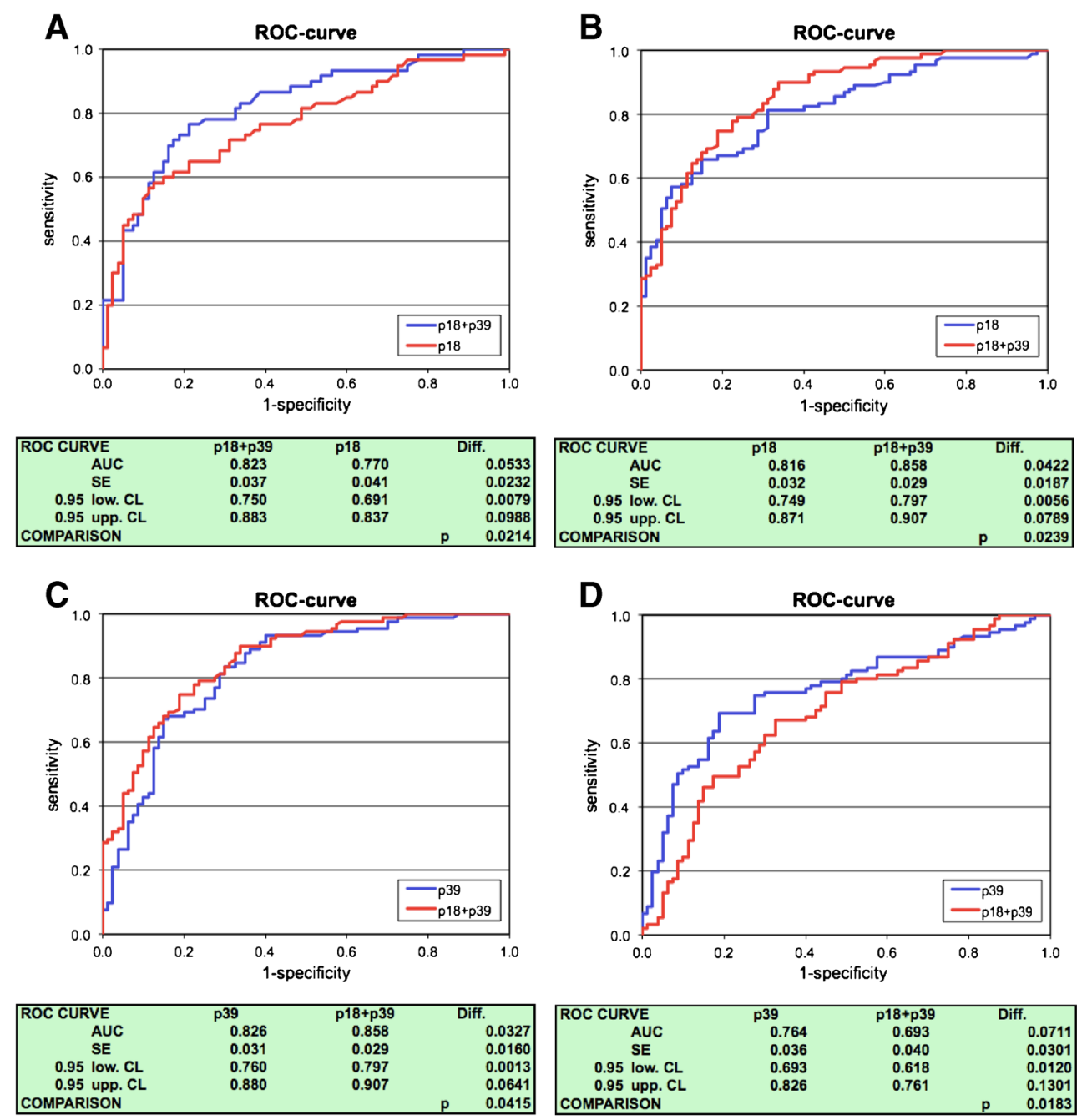

P39 ELISA. The WCL-based blot showed a sensitivity of $28.6 \%$ and a specificity of $96.2 \%$ in the detection of IgA antibodies and a sensitivity of $48.6 \%$ and a specificity of $83.8 \%$ in the detection of IgG antibodies.

These results show that a line blot or an ELISA based on antigen P39 and OMP18 have the highest sensitivity and specificity. Also, incorporation of antigens PEB1, PEB2, PEB4, and MOMP into line blot does not significantly improve sensitivity or specificity (Table 1 ).

Evaluation of $\operatorname{IgA}, \operatorname{IgG}$ and $\operatorname{Ig} \mathrm{A} / \mathrm{IgG}$ reactivity in $\mathrm{BD}, \mathrm{AE}$, GBS, RA and IBD sera

OMP18+P39-based ELISA for detection of antibody IgA and P39-based ELISA for detection of antibody IgG were used to determine the Campylobacter seroprevalence in BD, AE, GBS, RA and IBD sera.

As shown in Table 2, the reactivity of $\operatorname{IgA}$ antibodies in $\mathrm{BD}$ sera was 9-12\%, in culture-positive AE sera 35-45\% $(p<0.001)$, in GBS sera 48-55\% $(p<0.001)$, in RA sera 34 $40 \%(p<0.05)$ and in IBD sera it was $26-31 \%(p<0.05)$.
Campylobacter-specific IgA antibody prevalence was high in GBS followed by AE, RA and IBD sera in that order.

As shown in the same table, the P39-based prevalence of Campylobacter-specific IgG antibodies in BD was 9-17\%, in AE it was 52-62\%, in GBS 37-53\%, in RA 54-66\%, and in IBD it was $44-47 \%(p<0.001)$. Campylobacter-specific IgG antibody prevalence was high in RA sera followed by AE, IBD and GBS sera in that order.

Combined $\mathrm{IgA} / \mathrm{IgG}$ reactivity was found to be $16-26 \%$ in $\mathrm{BD}, 62-72 \%$ in AE, $60-65 \%$ in GBS, $70-78 \%$ in RA and $49-56 \%$ in IBD sera.

Comparison of $H$. pylori, M. pneumoniae, Y. enterocolitica, and $B$. afzelii specific antibody prevalences in AE, GBS, RA, IBD and BD sera

There was no significant difference in $H$. pylori-specific antibody-prevalence in AE, RA, and IBD patient sera compared to BD sera. However, antibody-prevalence of $H$. pylorispecific IgA in GBS sera was significantly higher (Table 2); 9-17\% anti-Campylobacter and anti-Helicobacter antibody 
Table 1 Sensitivity, specificity, positive (PPV) and negative predictive values (NPV) estimated on sera of stool culture positive campylobacteriosis patients and healthy blood donors

\begin{tabular}{|c|c|c|c|c|c|c|c|c|}
\hline \multirow[t]{2}{*}{ Antigen } & \multicolumn{2}{|c|}{$\begin{array}{l}\text { Sensitivity } \\
{[\%]}\end{array}$} & \multicolumn{2}{|c|}{$\begin{array}{l}\text { Specificity } \\
{[\%]}\end{array}$} & \multicolumn{2}{|c|}{ PPV [\%] } & \multicolumn{2}{|c|}{ NPV $[\%$} \\
\hline & $\operatorname{IgA}$ & IgG & $\operatorname{IgA}$ & IgG & $\operatorname{Ig} \mathrm{A}$ & IgG & $\operatorname{Ig} \mathrm{A}$ & $\operatorname{Ig}$ \\
\hline OMP18 ELISA & 57.1 & 51.9 & 90.5 & 90.8 & 82.1 & 79.4 & 73.6 & \\
\hline P39 ELISA & 40.7 & 57.4 & 90.9 & 90.5 & 75.9 & 81.6 & 68.6 & 74. \\
\hline OMP18+P39 ELISA & 38.9 & 47.3 & 91.0 & 90.8 & 75.0 & 78.8 & 68.3 & 70. \\
\hline MOMP MG & 18.3 & 3.3 & 100 & 96.3 & 100 & 40.0 & 62.0 & 57. \\
\hline PEB4 MG & 16.7 & 3.3 & 100 & 98.8 & 100 & 66.7 & 61.5 & 57.7 \\
\hline PEB2 MG & 3.3 & 1.7 & 100 & 100 & 100 & 100 & 57.9 & 57. \\
\hline PEB1 MG & 0.0 & 1.7 & 100 & 97.5 & - & 33.3 & 57.1 & 56. \\
\hline OMP18 MG & 41.7 & 36.7 & 100 & 98.8 & 100 & 95.7 & 69.6 & 67. \\
\hline P39 MG & 41.7 & 45.0 & 98.8 & 86.3 & 96.2 & 71.0 & 69.3 & 67. \\
\hline Index MG & 56.7 & 50.0 & 98.8 & 83.8 & 97.1 & 69.8 & 75.2 & 69. \\
\hline WCL & 28.6 & 48.6 & 96.2 & 83.8 & 76.9 & 58.6 & 75.0 & 77 \\
\hline
\end{tabular}

OMP18 outer membrane protein $18 \mathrm{kDa}, P 39$ protein $39 \mathrm{kDa}, M O M P$ major outer membrane protein, $P E B 1-4$ perplasmic-binding proteins $1-4$, Index $M G$ numerical index for test evaluation that is the sum of the ascribed points of all positive antigens, i.e. bands with coloration more intense than the cut-off band, $W C L$ whole cell lysate

double positive sera were found in all sera (AE, GBS, RA, IBD, and BD sera). See Table 3 for a particular group.

There was no significant difference in reactivity of antiM. pneumonia IgA-antibodies in all sera. But there was a significant increase $(p<0.05)$ in the reactivity of M. pneumonia-specific IgG in AE, RA, and IBD sera but not in GBS sera (Table 2); 16-23\% of all tested sera were positive for both anti-Campylobacter antibodies and antiM. pneumonia antibodies (Table 3); $4 \%$ of GBS sera that were negative for anti-Campylobacter-reactive antibodies showed both IgA and IgG antibodies reactive against M. pneumonia. The anti-Campylobacter antibody and antiM. pneumonia antibody double-positive (IgA and $\mathrm{IgG}$ ) rate was $23-33 \%$ in GBS sera (results not shown).

The prevalence of $Y$. enterocolitica-reactive IgA antibodies significantly increased $(p<0.05)$ in GBS, RA, AE, and IBD sera. $Y$. enterocolitica-reactive $\operatorname{IgG}$ antibodies significantly increased $(p<0.001)$ in only RA sera. Also, $15-18 \%$ ( $\operatorname{IgA})$, $8-11 \%(\operatorname{IgG})$, and $23-35 \%(\operatorname{IgA}+\operatorname{IgG})$ of all tested sera were positive for both $Y$. enterocolitica- and Campylobacter-reactive antibodies (Table 3). Specifically, a significant increase of double-positive rate for $\operatorname{IgA}$ antibodies was $17-30 \%$ in $\mathrm{AE}$, $19-26 \%$ in GBS and $18-26 \%$ in RA sera. Increase of doublepositive rate for IgG was $14-16 \%$ in RA sera only. AntiYersinia antibodies $(\operatorname{IgA} / \operatorname{IgG})$ in Campylobacter antibodynegative sera were found in $3-18 \% / 3-5 \%$ of AE, $12-$ $19 \% / 7-9 \%$ of GBS, $10-12 \% / 6-14 \%$ of RA, and $5-10 \% /$ $8-13 \%$ of IBD sera.
No significant difference in anti-B. afzelii-IgG antibody prevalence was observed between RA and BD sera. However, there was a significant increase $(p<0.05)$ in the prevalence of anti-B. afzelii-IgG antibodies in AE, GBS, and IBD patients; $13-22 \%$ of all tested sera were antiCampylobacter IgA and IgG antibody and anti-Borrelia IgG antibody double positive (Table 3). This double-positive rate was significantly $(p<0.05)$ above average in GBS patients (26-30\%) but below average in RA-patients (6\%) (results not shown).

\section{Discussion}

In a generation of seroprevalence data, antigen or antigen combination is decisive for the test concerned. Generally, the reactivity of the immunoglobulin classes $\operatorname{IgA}$ and $\operatorname{IgG}$ is determined in Campylobacter serodiagnostics because they have been found to have high sensitivity [25]. Immunoglobulin class IgM is rarely used because of its low sensitivity [23, 25]. Routine serodiagnostics of prior $C$. jejuniinfections is performed using an ELISA or an immunoblot with whole cell lysate or recombinant antigens [20, 23, 25]. Recombinant antigens including MOMP [26, 27], OMP18 [28], P39 [22], Cj0069 [20], and PEB 1, PEB 2, PEB 3, and PEB 4 [29] are used to detect Campylobacter specific antibodies. However, the sensitivity of OMP18 and P39 in relation to MOMP, PEB1, PEB2, PEB3 and PEB4 is unknown.

Therefore, one of the objectives of this study was to determine which antigen between OMP18, P39 and antigen combination (OMP18+P39) is the most sensitive and specific for detecting anti-Campylobacter antibodies in the diagnosis of acute campylobacteriosis and post-infectious sequelae. According to our data, an ELISA based on the combination of OMP18+P39 shows the ROC AUC maximum for IgA antibodies whereas an ELISA based on P39 alone exhibits the maximal ROC AUC for IgG antibodies. Antigens P39 and OMP18 as part of the MIKROGEN recomLine blot show almost the same values for sensitivity, specificity, PPV and NPV as those of antigens P39 and OMP18 being part of an ELISA. Therefore, it is evident that a line blot or an ELISA based only on antigens P39 and OMP18+P39 are the most sensitive and specific in detecting Campylobacter-specific antibodies in all patient groups. Additional detection of antiMOMP, -PEB1, -PEB2, and -PEB4 immune reactivity does not significantly improve Campylobacter serology. Consequently, the testing of antibodies using these antigens in Campylobacter serology should be discouraged and testing of antibodies using P39 and OMP18+P39 encouraged.

In this study $16-26 \%$ of healthy BD tested positive for both Campylobacter-specific $\operatorname{IgA}$ and $\operatorname{IgG}$ antibodies. The serum samples of the healthy blood donors were collected during a summer month in which the Campylobacter 


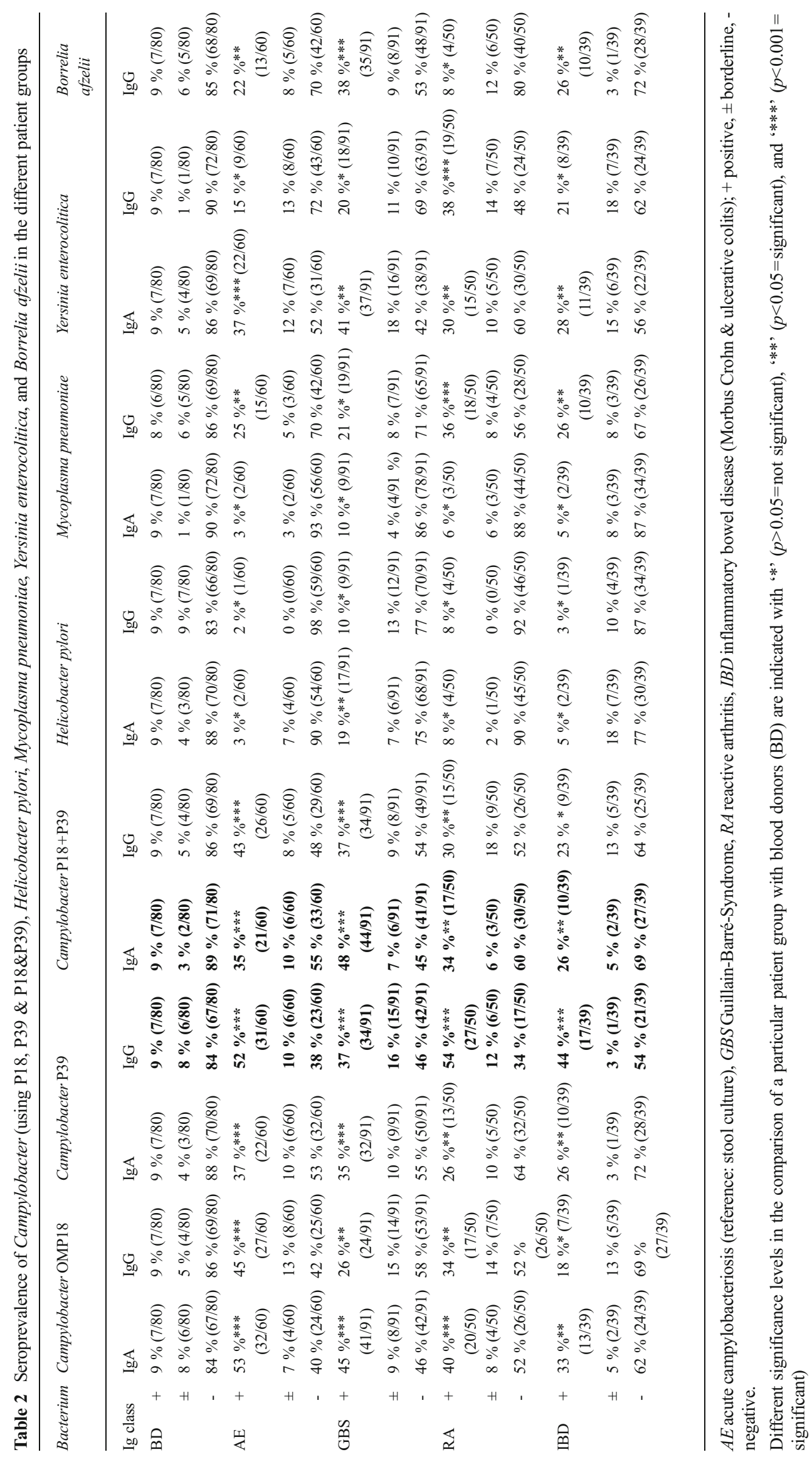


Table 3 Percentages and absolute numbers of Campylobacter-, Helicobacter pylori-, Mycoplasma pneumonia-, Yersinia enterocolitica-, and Borrelia afzelii-positive tested (IgA and $\mathrm{IgG}$ ) serum samples as well as percentages and absolute numbers of double positive tested serum samples in all 320 tested patients and blood donors

\begin{tabular}{|c|c|c|c|c|c|}
\hline Bacterium & $\begin{array}{l}\text { Campylobacter } \operatorname{IgA}^{+} \\
\text {or } \operatorname{IgG}^{+}\end{array}$ & $\begin{array}{l}\text { Helicobacter pylori } \\
\operatorname{IgA}^{+} \text {or } \operatorname{IgG}^{+}\end{array}$ & $\begin{array}{l}\text { Mycoplasma pneumoniae } \\
\mathrm{IgA}^{+} \text {or } \mathrm{IgG}^{+}\end{array}$ & $\begin{array}{l}\text { Yersinia enterocolitica } \\
\operatorname{IgA}^{+} \text {or } \operatorname{IgG}^{+}\end{array}$ & $\begin{array}{l}\text { Borrelia } \\
\text { afzelii } \operatorname{IgG}^{+}\end{array}$ \\
\hline $\begin{array}{c}\text { Campylobacter } \\
\text { IgA }^{+} \text {or } \text { IgG }^{+}\end{array}$ & $50-57 \%(159-183)$ & $9-17 \%(28-53)$ & $16-23 \%(51-75)$ & $23-35 \%(75-112)$ & $13-22 \%(42-70)$ \\
\hline $\begin{array}{l}\text { Helicobacter pylori } \\
\text { IgA }^{+} \text {or } \text { IgG }^{+}\end{array}$ & $9-17 \%(28-53)$ & $13-23 \%(43-73)$ & $4-11 \%(13-34)$ & $6-14 \%(19-46)$ & $5-11 \%(15-35)$ \\
\hline $\begin{array}{l}\text { Mycoplasma pneumoniae } \\
\text { IgA }^{+} \text {or } \text { IgG }^{+}\end{array}$ & $16-23 \%(51-75)$ & $4-11 \%(13-34)$ & $25-34 \%(80-108)$ & $11-21 \%(34-68)$ & $6-13 \%(18-40)$ \\
\hline $\begin{array}{l}\text { Yersinia enterocolitica } \\
\qquad \operatorname{IgA}^{+} \text {or } \text { IgG }^{+}\end{array}$ & $23-35 \%(75-112)$ & $6-14 \%(19-46)$ & $11-21 \%(34-68)$ & $34-50 \%(110-159)$ & $11-19 \%(35-61)$ \\
\hline Borrelia afzelii $\mathrm{IgG}^{+}$ & $13-22 \%(42-70)$ & $5-11 \%(15-35)$ & $6-13 \%(18-40)$ & $11-19 \%(35-61)$ & $22-29 \%(69-94)$ \\
\hline
\end{tabular}

Percentages are given in relation to all 320 serum samples included in this study. The absolute numbers of positive until positive plus borderline tested sera is given in brackets

prevalence is higher than in the winter months [30]. This might explain the increased prevalence rate of Campylobacter-specific antibodies in the healthy blood donor cohort in comparison to our previous studies [21, 22]. Similarly, 60-65\% of GBS patients tested positive for both Campylobacter-specific IgA and IgG antibodies; it therefore follows that $34-49 \%(\approx 42 \%)$ of GBS cases in this study are statistically associated with campylobacteriosis. Several studies have investigated the proportion of Campylobacter-triggered GBS and given an impression of an increase in Campylobacter associated GBS over time. For example, Winer et al. attributed $14 \%$ [31], Rees et al. attributed $26 \%$ [32], Jacobs et al. attributed $32 \%$ [33], Hao et al. attributed $45 \%$ [34] and our group attributed $80 \%$ [21] of GBS cases to Campylobacter. This increase in the detection of seroprevalence can been attributed to improved detection methods. In this study, our data on German patients supports the findings of Hao et al. who associated $45 \%$ of GBS cases with a prior Campylobacter infection in a study on a Japanese population [34] but varies from other studies which underestimated [31-33] or overestimated [21] the proportion of postCampylobacter GBS. However, the varying proportion of AMAN, AMSAN and MFS cases that have been demonstrated to be associated with a prior Campylobacter infection relative to AIDP cases in GBS study populations [6] could be another reason for these differences in the prevalence of Campylobacter-specific antibodies. Future studies are required to address this thought.

Furthermore, we tested all GBS sera for H. pylori-, M. pneumoniae-, Y. enterocolitica, and B. afzelii-reactive antibodies. The relatively high rate of double Mycoplasma- and Campylobacter-positive sera of GBS patients (23-33\%) indicates that there could be additive effects triggering autoantibodies causing GBS by sequential (or simultaneous) infections with $M$. pneumoniae and $C$. jejuni. Otherwise, there could be significant test cross-reactivity between both bacterial species. The rate of $4 \%$ of Mycoplasma-antibody positivity in Campylobacter-negative GBS-patients substantiates our data for Campylobacter seroprevalence in GBS patients, because it delivers valid data explaining the etiology of the remaining Campylobacter-negative GBS cases.

In contrast to that, the increased rate of double Borrelia and Campylobacter seropositive GBS patients (26-30\%) indicates an association between Campylobacter-triggered neuronal disease and neuroborreliosis either in antigenic interference (serodiagnostics) or even in etiology.

In the present study, we demonstrate a Campylobacter seroprevalence $(\mathrm{IgA}+\mathrm{IgG})$ rate of $70-78 \%$ in RA patients. By subtracting the prevalence of Campylobacter-specific antibodies (16-26\%) of healthy BD, about 44-62\% ( $\approx 53 \%$ ) of RA cases are associable with Campylobacter. Moreover, tests to determine H. pylori-, M. pneumoniae-, Y. enterocolitica-, and $B$. afzelii-reactive antibodies in all the sera showed higher Campylobacter-specific antibodies than those of other pathogens. The association of yersiniosis and RA is well described $[35,36]$ and reconfirmed by the seroprevalence data of this study. The relatively low B. afzelii seroprevalence rate (8$20 \%$ ) as well as the low rate of double Borrelia and Campylobacter antibody-positive sera in RA patients $(6 \%)$ indicates that the subgroup of Borrelia-reactive arthritis interferes only to a minor degree with post-Campylobacter RA.

One debatable question is the contribution of Campylobacter caused episodes of acute gastroenteritis to the pathogenesis of IBD. Recent investigations in gnotobiotic mice demonstrated that the composition of the intestinal flora plays a pivotal role in the pathogenesis of acute campylobacteriosis. Due to their microbiota composition, mice display a natural colonization resistance against C. jejuni [16, 17]. Quantitative analysis of the bacterial gut flora composition revealed two- to three-fold increased Escherichia coli loads in intestinal 'humanized' mice that are susceptible to $C$. jejuni compared to resistant mice recolonized 
with a murine gut flora [16, 17]. Likewise, high-elevated E. coli amounts increase the susceptibility to $S$. enterica-caused enteritis in mice [37-39]. Here a vicious circle starts because intestinal inflammation is associated with remarkable changes in the gut microbiota. Intestinal inflammation results in a decrease in the diversity of natural bacterial species in the gut leading to overgrowth of commensals such as E. coli, Bacteroides spp., and Prevotella spp. [40-44]. This dysbiosis in turn increases the susceptibility for $C$. jejuni- and $S$. enterica-caused enteritis. Additionally it was shown that E. coli LPS triggers TLR-4signalling, which is a key signal for initiation and continuation of enteritis [41, 42]. Continuous inflammation is one pivotal parameter in the multifactorial pathogenesis of IBD $[13,45]$. In this regard we are faced with a delicate codependency situation. On one hand, IBD patients are more susceptible to enteric pathogens $[13,45,46]$, while on the other hand, recurrent episodes of acute bacterial enterocolitis trigger the manifestation of IBD in susceptible individuals [11, 12, 47]. Thus, the significantly $(p<0.001)$ increased Campylobacter-seroprevalence in IBD patients, which ranges from 23 to $40 \%$ $(\approx 32 \%)$, subtracting the prevalence of Campylobacter-specific antibodies in 16-26\% of healthy individuals (BD) in our study, supports the theory of campylobacteriosis-triggerd IBD as well as the theory of an increased susceptibility for Campylobacter in IBD patients. Recent studies performed on rodent mice have revealed that $H$. hepaticus and $H$. bilis employ the same mechanism to trigger IBD [48]. Therefore, further studies are required to determine if a similar situation applies to other enteric pathogens.

The overall low H. pylori-seroprevalence rate (13-23\%) and especially the low rate of double Helicobacter-and Campylobacter-reactive sera (9-17\%) indicates that there is very little influence of cross-reactivity between both bacterial species in this study. The reasonably high rate of Yersiniaantibody positive sera especially among patients who were also tested Campylobacter-seropositive may be explained by unspecific (re-) activation of the specific intestinal immune response against an intestinal pathogen (especially in IBD) but also by antigenic interference, that would be a significant weakness in Campylobacter serodiagnostics. Therefore, this aspect has to be further addressed in future studies.

In conclusion, we show that antigens OMP18+P39 (for IgA) and P39 (for IgG) have larger ROC AUCs than WCL, OMP18, MOMP, PEB1, PEB2 and PEB4 antigens. Therefore, their usage in diagnostics of previous Campylobacter infections will produce much more reliable results. In addition, we present valid data showing that a higher proportion of post-infectious sequelae, namely, GBS, RA and IBD are triggered by Campylobacter spp. as compared to H. pylori, M. pneumoniae, Y. enterocolitica, and Borellia spp. However, there is evidence for codependency between Campylobacter infections and infections with these pathogens to trigger particular post infectious sequelae. Therefore, further studies should address how the sum of antibodies specific for these pathogens increases the risk to trigger a particular post infectious sequel and to which extent cross-reactivity of these antibodies affects the specificity of diagnostic tests.

Acknowledgments We thank Sonja Stimpfig and Christiane Scholz for excellent technical assistance, and we are grateful to David Hunt for revising the text of the manuscript.

Financial support The authors' work was supported by the Deutsche Forschungsgemeinschaft (GR 906/13-1) and the Forschungsförderungsprogramm of the Universitätsmedizin Göttingen, Germany. This publication was funded by the Open Access support program of the Deutsche Forschungsgemeinschaft and the publication fund of the Georg August Universität Göttingen.

Potential conflicts of interest All authors report no potential conflicts of interest.

Open Access This article is distributed under the terms of the Creative Commons Attribution License which permits any use, distribution, and reproduction in any medium, provided the original author(s) and the source are credited.

\section{References}

1. Allos BM (1997) Association between Campylobacter infection and Guillain-Barre syndrome. J Infect Dis 176(Suppl 2):S125-S128

2. Nachamkin I, Allos BM, Ho T (1998) Campylobacter species and Guillain-Barre syndrome. Clin Microbiol Rev 11(3):555-567

3. Butzler JP (2004) Campylobacter, from obscurity to celebrity. Clin Microbiol Infect: Off Publ Eur Soc Clin Microbiol Infect Dis 10(10): 868-876

4. Dasti JI, Tareen AM, Lugert R, Zautner AE, Groß U (2010) Campylobacter jejuni: a brief overview on pathogenicity-associated factors and disease-mediating mechanisms. Int J Med Microbiol: IJMM 300(4):205-211

5. Zautner AE, Herrmann S, Groß U (2010) Campylobacter jejuniThe search for virulence-associated factors. Arch Leb 61(3):91-101

6. Schwerer B (2002) Antibodies against gangliosides: a link between preceding infection and immunopathogenesis of Guillain-Barre syndrome. Microbes Infect/Inst Pasteur 4(3):373-384

7. Pope JE, Krizova A, Garg AX, Thiessen-Philbrook H, Ouimet JM (2007) Campylobacter reactive arthritis: a systematic review. Semin Arthritis Rheum 37(1):48-55

8. Mortensen NP, Kuijf ML, Ang CW, Schiellerup P, Krogfelt KA, Jacobs BC, van Belkum A, Endtz HP, Bergman MP (2009) Sialylation of Campylobacter jejuni lipo-oligosaccharides is associated with severe gastro-enteritis and reactive arthritis. Microbes Infect/Inst Pasteur 11(12):988-994

9. Townes JM (2010) Reactive arthritis after enteric infections in the United States: the problem of definition. Clin Infect Dis: Off Publ Infect Dis Soc Am 50(2):247-254

10. Hannu T, Mattila L, Rautelin H, Pelkonen P, Lahdenne P, Siitonen A, Leirisalo-Repo M (2002) Campylobacter-triggered reactive arthritis: a population-based study. Rheumatology 41(3):312-318

11. Garcia Rodriguez LA, Ruigomez A, Panes J (2006) Acute gastroenteritis is followed by an increased risk of inflammatory bowel disease. Gastroenterology 130(6):1588-1594

12. Gradel KO, Nielsen HL, Schonheyder HC, Ejlertsen T, Kristensen B, Nielsen H (2009) Increased short- and long-term risk of inflammatory 
bowel disease after salmonella or campylobacter gastroenteritis. Gastroenterology 137(2):495-501

13. Jess T, Simonsen J, Nielsen NM, Jorgensen KT, Bager P, Ethelberg S, Frisch M (2011) Enteric Salmonella or Campylobacter infections and the risk of inflammatory bowel disease. Gut 60(3):318-324

14. Riddle MS, Gutierrez RL, Verdu EF, Porter CK (2012) The chronic gastrointestinal consequences associated with campylobacter. Curr Gastroenterol Rep 14(5):395-405

15. Masanta WO, Heimesaat MM, Bereswill S, Tareen AM, Lugert R, Groß U, Zautner AE (2013) Modification of intestinal microbiota and its consequences for innate immune response in the pathogenesis of campylobacteriosis. Clin Dev Immunol 2013:10

16. Bereswill S, Fischer A, Plickert R, Haag LM, Otto B, Kuhl AA, Dasti JI, Zautner AE, Munoz M, Loddenkemper C, Groß U, Gobel UB, Heimesaat MM (2011) Novel murine infection models provide deep insights into the "menage a trois" of Campylobacter jejuni, microbiota and host innate immunity. PLoS ONE 6(6):e20953

17. Bereswill S, Plickert R, Fischer A, Khül AA, Loddenkemper C, Batra A, Siegmund B, Göbel UB, Heimesaat MM (2011) What you eat is what you get: Novel Campylobacter models in the quadrangle relationship between nutrition, obesity, microbiota and susceptibility to infection. Eur J Microbiol Immunol 1(3):237-248

18. Boswell TC, Kudesia G (1992) Serological cross-reaction between Legionella pneumophila and campylobacter in the indirect fluorescent antibody test. Epidemiol Infect 109(2):291-295

19. Colmegna I, Cuchacovich R, Espinoza LR (2004) HLA-B27associated reactive arthritis: pathogenetic and clinical considerations. Clin Microbiol Rev 17(2):348-369

20. Corso J, Lugert R, Groß U, Zautner AE (2011) Is the Campylobacter jejuni secretory protein $\mathrm{Cj} 0069$ a suitable antigen for serodiagnostics? Eur J Microbiol Immunol 1(1):86-94

21. Schmidt-Ott R, Schmidt H, Feldmann S, Brass F, Krone B, Groß U (2006) Improved serological diagnosis stresses the major role of Campylobacter jejuni in triggering Guillain-Barre syndrome. Clin Vaccine Immunol: CVI 13(7):779-783

22. Schmidt-Ott R, Brass F, Scholz C, Werner C, Groß U (2005) Improved serodiagnosis of Campylobacter jejuni infections using recombinant antigens. J Med Microbiol 54(Pt 8):761-767

23. Enders U, Karch H, Toyka KV, Michels M, Zielasek J, Pette M, Heesemann J, Hartung HP (1993) The spectrum of immune responses to Campylobacter jejuni and glycoconjugates in GuillainBarre syndrome and in other neuroimmunological disorders. Ann Neurol 34(2):136-144

24. Maeland JA, Bevanger L, Enge J (1993) Serological testing for campylobacteriosis with sera forwarded for Salmonella and Yersinia serology. APMIS: Acta Pathol Microbiol Immunol Scand 101(8):647-650

25. Strid MA, Engberg J, Larsen LB, Begtrup K, Molbak K, Krogfelt KA (2001) Antibody responses to Campylobacter infections determined by an enzyme-linked immunosorbent assay: 2-year follow-up study of 210 patients. Clin Diagn Lab Immunol 8(2):314-319

26. Blaser MJ, Duncan DJ (1984) Human serum antibody response to Campylobacter jejuni infection as measured in an enzyme-linked immunosorbent assay. Infect Immun 44(2):292-298

27. Blaser MJ, Hopkins JA, Vasil ML (1984) Campylobacter jejuni outer membrane proteins are antigenic for humans. Infect Immun 43(3): 986-993

28. Burnens A, Stucki U, Nicolet J, Frey J (1995) Identification and characterization of an immunogenic outer membrane protein of Campylobacter jejuni. J Clin Microbiol 33(11):2826-2832

29. Pei ZH, Ellison RT 3rd, Blaser MJ (1991) Identification, purification, and characterization of major antigenic proteins of Campylobacter jejuni. J Biol Chem 266(25):16363-16369

30. Sopwith W, Birtles A, Matthews M, Fox A, Gee S, Painter M, Regan M, Syed Q, Bolton E (2008) Identification of potential environmentally adapted Campylobacter jejuni strain, United Kingdom. Emerg Infect Dis 14(11):1769-1773

31. Winer JB, Hughes RA, Anderson MJ, Jones DM, Kangro H, Watkins RP (1988) A prospective study of acute idiopathic neuropathy. II. Antecedent events. J Neurol Neurosurg Psychiatry 51(5):613-618

32. Rees JH, Soudain SE, Gregson NA, Hughes RA (1995) Campylobacter jejuni infection and Guillain-Barre syndrome. N Engl J Med 333(21):1374-1379

33. Jacobs BC, van Doorn PA, Schmitz PI, Tio-Gillen AP, Herbrink P, Visser LH, Hooijkass H, van der Meche FG (1996) Campylobacter jejuni infections and anti-GM1 antibodies in Guillain-Barre syndrome. Ann Neurol 40(2):181-187

34. Hao Q, Saida T, Kuroki S, Nishimura M, Nukina M, Obayashi H, Saida K (1998) Antibodies to gangliosides and galactocerebroside in patients with Guillain-Barre syndrome with preceding Campylobacter jejuni and other identified infections. J Neuroimmunol 81(1-2):116-126

35. Cover TL, Aber RC (1989) Yersinia enterocolitica. N Engl J Med 321(1):16-24

36. Bottone EJ (1997) Yersinia enterocolitica: the charisma continues. Clin Microbiol Rev 10(2):257-276

37. Stecher B, Chaffron S, Kappeli R, Hapfelmeier S, Freedrich S, Weber TC, Kirundi J, Suar M, McCoy KD, von Mering C, Macpherson AJ, Hardt WD (2010) Like will to like: abundances of closely related species can predict susceptibility to intestinal colonization by pathogenic and commensal bacteria. PloS Pathog 6(1):e1000711

38. Stecher B, Hardt WD (2011) Mechanisms controlling pathogen colonization of the gut. Curr Opin Microbiol 14(1):82-91

39. Stecher B, Robbiani R, Walker AW, Westendorf AM, Barthel M, Kremer M, Chaffron S, Macpherson AJ, Buer J, Parkhill J, Dougan G, von Mering C, Hardt WD (2007) Salmonella enterica serovar typhimurium exploits inflammation to compete with the intestinal microbiota. PLoS Biol 5(10):2177-2189

40. Heimesaat MM, Bereswill S, Fischer A, Fuchs D, Struck D, Niebergall J, Jahn HK, Dunay IR, Moter A, Gescher DM, Schumann RR, Gobel UB, Liesenfeld $O$ (2006) Gram-negative bacteria aggravate murine small intestinal Th1-type immunopathology following oral infection with Toxoplasma gondii. J Immunol 177(12):8785-8795

41. Heimesaat MM, Fischer A, Jahn HK, Niebergall J, Freudenberg M, Blaut M, Liesenfeld O, Schumann RR, Gobel UB, Bereswill S (2007) Exacerbation of murine ileitis by Toll-like receptor 4 mediated sensing of lipopolysaccharide from commensal Escherichia coli. Gut 56(7):941-948

42. Heimesaat MM, Fischer A, Siegmund B, Kupz A, Niebergall J, Fuchs D, Jahn HK, Freudenberg M, Loddenkemper C, Batra A, Lehr HA, Liesenfeld O, Blaut M, Gobel UB, Schumann RR, Bereswill S (2007) Shift towards pro-inflammatory intestinal bacteria aggravates acute murine colitis via Toll-like receptors 2 and 4. PLoS ONE 2(7):e662

43. Wohlgemuth S, Keller S, Kertscher R, Stadion M, Haller D, Kisling S, Jahreis G, Blaut M, Loh G (2011) Intestinal steroid profiles and microbiota composition in colitic mice. Gut Microbes 2(3):159-166

44. Haag LM, Fischer A, Otto B, Plickert R, Kühl AA, Gobel UB, Bereswill S, Heimesaat MM (2012) Intestinal microbiota shifts towards elevated commensal Escherichia coli loads abrogate colonization resistance against Campylobacter jejuni in mice. PLoS ONE 7(5):e35988

45. Kalischuk LD, Buret AG (2010) A role for Campylobacter jejuniinduced enteritis in inflammatory bowel disease? Am J Physiol Gastrointest Liver Physiol 298(1):G1-G9

46. Man SM, Kaakoush NO, Mitchell HM (2011) The role of bacteria and pattern-recognition receptors in Crohn's disease. Nat Rev Gastroenterol Hepatol 8(3):152-168

47. Helms M, Simonsen J, Molbak K (2006) Foodborne bacterial infection and hospitalization: a registry-based study. Clin Infect Dis: Off Publ Infect Dis Soc Am 42(4):498-506

48. Hansen R, Thomson JM, Fox JG, El-Omar EM, Hold GL (2011) Could Helicobacter organisms cause inflammatory bowel disease? FEMS Immunol Med Microbiol 61(1):1-14 